\title{
А. А. Сукало
}

\section{Профилактика насилия в современном социокультурном контексте}

В статье в контексте современного общественного дискурса рассматривается проблема профилактики насилия. Актуализация данной проблематики связана с обсуждением проекта закона «О семейно-бытовом насилии», инициированном рядом некоммерческих организаций в соответствии со «Стамбульской конвенцией Совета Европы о предотвращении и борьбе с насилием в отношении женщин и домашним насилием 2011г.». По их мнению, в Российской Федерации женщины практически не защищены от семейного насилия и мужского произвола. Однако это не соответствует существующей законодательной базе и сложившейся многоаспектной практике профилактики насильственных проявлений различного вида, не подтверждается статистическими данными, противоречит культурным традициям. Отечественная система профилактики опирается на комплекс правовых, психолого-педагогических, социально-культурных мер противодействия насилию. Информационные вбросы и лоббирование законодательных решений преследуют четыре основные цели, связанные с деконструкцией сложившейся системы профилактики насилия и девальвацией института семьи. Социокультурные и педагогические стратегии укрепления семьи, защиты детства и материнства должны явиться основой современного инструментария педагогической деятельности, а также противодействия манипулятивным практикам.

Ключевые слова: профилактика насилия, манипулятивные практики, информационные технологии, защита семьи и детства, социально-культурная деятельность, недирективная педагогика

\section{Aleksandr A. Sukalo}

\section{Prevention of violence in the contemporary sociocultural context}

The article, in the context of modern public discourse, examines the problem of violence prevention. The actualization of this issue is related to the discussion of the draft law «On Domestic Violence», initiated by a number of non-profit organizations in accordance with the «Istanbul Convention of the Council of Europe on the Prevention and Combating of Violence against Women and Domestic Violence 2011 ». According to them, in the Russian Federation women are practically not protected from domestic violence and male arbitrariness. However, this does not comply with the existing legislative framework and the prevailing multidimensional practice of preventing violent manifestations of various kinds, is not confirmed by statistical data, and contradicts cultural traditions. The domestic prevention system is based on a complex of legal, psychological, pedagogical, and socio-cultural measures to counter violence. Information throws and lobbying for legislative decisions pursue four main goals related to the deconstruction of the existing system for the prevention of violence and the devaluation of the institution of the family. Sociocultural and pedagogical strategies for strengthening the family, protecting childhood and motherhood should be the basis of modern tools of pedagogical activity as well as countering manipulative practices.

Keywords: violence prevention, manipulative practices, information technology, protection of the family and childhood, social and cultural activities, non-directive pedagogy

DOI 10.30725/2619-0303-2020-2-109-114

Проблема насилия и необходимость профилактики различных его проявлений в последнее время обрела значительный общественный резонанс. Это связано с попытками продвижения проекта закона о семейно-бытовом насилии в средствах массовой информации и посредством проведения различных акций рядом радикально ориентированных общественных объединений. В конце 2019 и начале 2020 гг. в данную дискуссию включились политики, общественные деятели, представители различных сфер искусства. И только драматические события весны 2020 г., связанные с пандемией коронавируса, на время приостановили обсуждение данной проблемы.

Основная аргументации сторонников принятия данного закона заключается в утверждении о якобы имеющем место росте в Российской
Федерации фактов семейного насилия, наличием аналогичных законодательных актов в ряде европейских государств, необходимостью подписания и ратификации международных документов (Стамбульской конвенции Совета Европы о предотвращении и борьбе с насилием в отношении женщин и домашним насилием, открытой к подписанию с 11 мая 2011 г. и вступившей в силу 1 августа 2014 г., подписанной 33 странами). В конвенции криминализированы (с 33 по 42 статью) психологическое насилие, преследование, физическое насилие, различные формы нанесения телесных повреждений, принудительный брак, принудительные аборты и стерилизация, а также частично криминализируются сексуальные домогательства (харрасмент) и преступления во имя так называемой «чести». 


\section{А. А. Сукало}

Критики данного проекта отстаивают точку зрения о том, что необходимость в принятии указанного закона отсутствует. В российском уголовном законодательстве криминализировано большинство указанных в конвенции преступлений, а введение гендерного равноправия 58 полов, легализация понятия «социальный пол», не совпадающего с биологическим, преследует совершенно иные цели.

В то же время проблема насилия, средств и методов его профилактики не является новой. Сложились отдельные научные направления - вайленсология (теория насилия, изучающая его различные формы, в первую очередь, политические), агрессология (теория агрессии, направленная, в значительной степени, на изучение детско-подростковых психологических реакций). Как форма поведения в различных его видах, насилие достаточно глубоко изучалось в социологических, криминологических, психологических и педагогических исследованиях.

Многосторонность и емкость проблематики, связанной с различными формами проявления насилия, широкий общественный резонанс, социальная актуальность и возможные негативные последствия для отечественной правоприменительной и педагогической практики складывающегося международного мейнстриминга, определяют необходимость рассмотрения феномена насилия также и в социокультурном контексте. Данный ракурс исследования позволит интегрировано осветить и осмыслить различные подходы в анализе проявлений насильственных практик, способов их предупреждения.

В современной превентологии как научного направления, изучающего широкий спектр средств, методов и форм предупреждения различных девиаций, проблема профилактики насилия является одним из приоритетных направлений научных исследований и социально-педагогических практик. Криминологи и девиантологи считают, что в значительном числе случаев насилие является производным и сопутствующим фактором, а также формой преступного и деструктивного поведения как отдельных лиц, так и малых групп. Насилие ради насилия (садизм, маниакальное сексуальное преследование, жестокое обращение с животными и др.) характерно для лиц с серьезными психопатологическими отклонениями. Такие лица требуют специальной коррекции и, при необходимости, ресоциализации в условиях закрытого типа.

Проявления насилия наиболее часто являются следствием конфликтов и латентных конфликтных ситуаций в различных сферах жизнедеятельности, обусловливаются стремлением к самоутверждению или подавлением воли лиц, воспринимаемых в качестве жертв или противников. Насилие является своеобразным инструментарием решения проблем взаимоотношений в криминальных и нарко-сообществах, средством совершения целого спектра преступлений. Насилие так же является формой проявления агрессивности (от лат. aggressiō - нападение), в основе которой присутствует сложное сочетание биопсихологических и социокультурных компонентов.

В широко известной работе швейцарского социолога и этолога Конрада Лоренца «Агрессия или так называемое зло» природа агрессивности и насилия объясняется этологической природой поведения человека, т. е. заимствованной в процессе эволюции мотивированной и немотивированной реакцией индивида на ту или иную ситуацию. Очевидно, бессознательные факторы, мотивирующие агрессивность, играют существенную роль в поведении индивида, но культурная эволюция человека позволила сформировать действенные механизмы блокировки и экстраполяции данных импульсов в социально-приемлемые формы индивидуального и группового поведения.

Проблема заключается в доминировании в общественной морали и установках степени приемлемости тех или иных насильственных практик. В случае их массовой оценки как категорически недопустимых, социум вырабатывает механизмы социальной регуляции, формирует ценностные основания применения правовых, информационных и педагогических механизмов обеспечения контроля негативных проявлений в различных сферах общественной жизни.

В числе социокультурных факторов, определяющих насильственные формы поведения индивида, - дефицит культуры в результате ненадлежащего воспитания, мировоззренческие установки, связанные с культом сильной личности, избранностью, этнической принадлежностью, индивидуализмом, эгоцентризмом. Существенную роль играет исторически сложившаяся криминальная субкультура, продвигаемая в социальных сетях так называемым АУЕ-сообществом (арестантскоуркаганским единством), позиционирующим себя в качестве особого деструктивного объединения.

Насилие проявляется, чаще всего, в таких формах, как: агрессивно-деструктивное поведение, школьные насильственные практики, семейно-бытовое насилие, буллинг (травля), сталкинг (преследование), сексуальное насилие, побои, истязание, издевательство, экстремизм, различные виды хулиганства и др. Насилие присутствует как в специфически мужских, так и женских сообществах. Бо́льшая часть данных проявлений криминализирована в уголовном законодательстве по строго определенным критериям и признакам преступлений.

В традиционной педагогике проявления насилия блокируются формированием регуляторов 
социального поведения, созданием системы позитивного ценностного отношения к правам и свободам другого человека. Правовое, нравственное воспитание, социальный контроль обеспечивали, в целом, в отечественной педагогической традиции и практике относительно эффективную систему регуляции поведения индивида и определяли направления формирования личности. Педагогические стратегии выстраивались на основе дополняющего правовые нормы инструментария профилактики насилия в любых его проявлениях. Правовой основой являлась, как отмечалось выше, криминализация насильственных действий и проявлений в группе «насильственные преступления» в уголовном законодательстве. В целом сложилась достаточно действенная система профилактики негативных явлений, в том числе и насильственных практик.

Деконструкция в 1990-е гг. сложившейся в СССР системы социального воспитания, включающая ликвидацию пионерской и комсомольской организаций, декларирование индивидуализма (в концептах прав человека и личных свобод) как ценностного ориентира, привели к редукции, прежде всего, в подростково-молодежных субкультурах понимания насилия и использования его как инструментария межличностной и межгрупповой коммуникации. Криминальная субкультура и деструктивные практики активно внедрялись в сферу досуга, а получившие опыт насилия молодые люди пополняли криминальные сообщества. Продвижение образа криминальных лидеров в качестве «культурных» эталонов, преимущественно в телевизионных сериалах, создало и создает до настоящего времени пространство трансформации соционормативных представлений у значительной части молодежи. Примерами провайдеров негативной аккультурации могут служить популярные в подростково-молодежной среде в предшествующие годы фильмы и сериалы: «Криминальное чтиво» Квентина Тарантино, «Бригада» Алексея Сидорова, «Бандитский Петербург» Владимира Бортко, «Черный бумер» Петра Буслова и др.

Референтация в подростково-молодежном сознании криминально-ориентированных лидеров и моделей их поведения в художественно-романтической транскрипции неизбежно приводит к использованию и популяризации насильственных практик. К сожалению, формирование потребительских ориентаций, культа успеха, сильной личности создает у молодых людей мотивационноповеденческие установки соответствующего типа.

Насильственные практики инверсировались в различные сферы социальных коммуникаций и межличностных отношений. В значительной степени подверженными данной тенденции оказались социально уязвимые и неблагополучные семьи, отношения в общеобразовательных учебных заведениях (в аспекте межличностных коммуникаций между учащимися и учащийся - учитель), отдельные субкультурные объединения. Обрели модельный статус деструктивные технологии насильственных практик, такие как буллицид - доведение детей и подростков до самоубийства путем психологического насилия, кибербуллинг (cyberbullying) - виртуальный террор. В контексте проявления насилия в отношении женщин сформировались понятия: «мизогинного поведения» (пристального наблюдения за женщиной); «фэтшейминга» (высмеивания за физические особенности); «объективации» (неуважение личного пространства женщин). Особое деструктивное значение применение насильственных практик обрело в группах криминального риска.

После принятия «Стамбульской конвенции Совета Европы» ряд зарегистрированных в Российской Федерации некоммерческих организаций, в том числе и объединений феминистической ориентации, развернули в 2019-2020 гг. достаточно активную кампанию по принятию законодательства о семейно-бытовом насилии, используя, в том числе, расширительную интерпретацию и детализацию форм проявлений насилия в документах Всемирной организации здравоохранения. Используя данную платформу, лоббисты законодательного решения кардинально модифицировали само понятие насилия, создав новую концепцию, в которой к различным формам проявления насильственных действий были добавлены его «скрытые» компоненты. Ссылаясь на труды малоизвестного у нас американского социолога Эвана Старка, автора концепции семейного насилия, активисты-общественники вслед за ним утверждают, что 90-99 \% насильственных действий в семье являются скрытыми. И только малую часть из них можно фиксировать в виде очевидных последствий (ссадин, синяков или явно криминальных действий). Отсюда контекстно проводится мысль о том, что семья и семейные отношения априори являются областью насилия в отношении женщин!

Абсолютно не важно, существует это в реальности или нет, какова современная статистика и правоприменительные практики, важна сама коннотация обозначенной проблемы. Созданный «фантом семейного насилия» стал технологическим объектом, вокруг которого осуществляется провоцирование и консолидация общественного мнения с использованием ресурсов СМИ и социальных сетей. Появились многочисленные жуткие фотографии подвергшихся насилию женщин, душераздирающие истории и исповеди жертв семейного насилия, сопровождаемые не менее эмоциональными комментариями к ним. Как следствие - обоснование необходимости применения превентивного «принуждения и контроля» К на- 


\section{А. А. Сукало}

сильникам. Но, в качестве такого (как мы помним, насилие «неявное»), может оказаться любой субъект мужского пола (в данном случае принцип социального гендера активистками не применяется). Основанием для применения санкций - выдвинутое обвинение. Несущественно, является оно достоверным или нет. С этого момента отношения в семье перестают быть внутренним делом семьи. Они особым образом переводятся в публичную и правовую сферы, где роль экспертов и консультантов присваивают лица-самозванцы, разработавшие уставы общественных объединений и наделившие себя полномочиями в качестве «борцов против несправедливости и жестокости».

Вот в это социокультурное, по сути, пространство, вторгаются определенные некоммерческие организации, которые де-факто присваивают себе оценочные и даже правоохранительные функции. Концентрируя информационный ресурс и целенаправленно популистки его используя в своих интересах, такие НКО и их представители вынуждают субъекты социальной профилактики и правоохранительные органы давать оправдательные объяснения, а иногда совершать нелогичные и поспешные действия. Это искусственно создает поля напряженности и пространство манипуляции общественным мнением.

Главная роль отводится формулированию, на основе якобы имеющихся фактов, ставшими уже классическими обвинений в том, что государство «ничего не может» или «ничего не делает». Белокасочная технология «психологического истеричного давления» здесь используется более утонченно. Если белые каски искусственно моделируют ложную ситуацию, привлекают нанятых исполнителей, то в случае семейного насилия разобраться в конкретных фактах и их подоплеке очень непросто. Это требует времени, привлечения профессионалов, которые осуществят социальное расследование условий жизни семьи, проведут опрос родственников и соседей, изучат имеющуюся документацию в случае, если семья стоит на профилактическом учете, совершат необходимые процедурно-профессиональные действия и вынесут более или менее объективное решение.

Вот как раз в этой точке между констатацией факта и его компетентным всесторонним анализом и происходит развертывание манипуляционных схем. В них заранее заданы поведенческие модели «насилия». Так обсуждение или спор по вопросам семейного бюджета возможно констатировать в качестве экономического насилия, установление режима дня для детей и ограничение пользования гаджетами квалифицировать как принуждающее или контролирующее действие. Продолжительный взгляд или комплимент расценивать в качестве харрасмента с последующими выводами т. п. Далее формируется ложная по своей сути, но правдоподобная по форме, «платформа общественного мнения» и включаются эмоционально окрашенные PR-практики, ориентированные на дестабилизацию правоохранительно-профилактической системы, и не только.

Согласно законодательству об общественных объединениях в Российской Федерации (ст. 17. Государство и общественные объединения, ст. 27. Права общественного объединения) государство не вмешивается в деятельность общественных объединений, но и общественные объединения не могут влиять на деятельность государственных структур и его представителей. но вместе с тем, согласно ст. 27, имеют набор прав, позволяющих «свободно распространять информацию о своей деятельности; участвовать в выработке решений органов государственной власти и органов местного самоуправления...»; «проводить собрания, митинги, демонстрации, шествия и пикетирование»; «учреждать средства массовой информации и осуществлять издательскую деятельность»; «представлять и защищать свои права, законные интересы своих членов и участников, а также других граждан в органах государственной власти, органах местного самоуправления и общественных объединениях» [3] и т. д.

Данный набор прав может быть использован как в созидательных целях, так и крайне деструктивно. Полномочия общественного объединения, реализуемые в манипулятивных интересах, позволяют, используя модифицированный концепт «насилия», развернуть тонкий информационный террор. Целей здесь несколько. Первая - дезорганизации деятельности правоохранительно-профилактической системы. Создать критическую перегрузку сотрудников - включить их в бесконечный разбор якобы насильственных ситуаций в семье (не рассматриваем пока ювенальную юстицию), возможно массовым вбросом заявительских материалов с требованиями немедленного реагирования. В то же время, в проектах закона о семейно-бытовом насилии предлагается выдача подозреваемым в насильственных действиях специальных ордеров для осуществления контроля их поведения, запрет приближаться ближе, чем на 50 м к потенциальной жертве. Предполагается также «кризисное замещение» (отселение, не очень понятно куда) на достаточно длительный срок, штрафы, принудительная психологическая терапия, создание специальных служб защиты и поддержки пострадавших от насилия (за счет каких средств?) и многие другие решения без определения реальных возможностей их кадрового, материального и иного ресурсного обеспечения.

Второй целью является переформатирование внутрисемейных отношений. Имплицитно, семья 
рассматривается как пространство борьбы всех против всех, в первую очередь, как сфера гендерной войны. В информационном дискурсе изначально утверждается модель семьи с распределением ролей: насильник-жертва, приоритетом требований (не прав!) ребенка перед правами и обязанностями родителей, а также допущение произвольного вмешательства ювенальных служб в семейные дела. В данной ситуации искусственно разрывается ткань семейных отношений, определяемая многочисленными культурно-историческими, этническими, религиозными, этическими факторами.

В отечественном социокультурном пространстве этнические и религиозные традиции и нормы обретают особое значение. Учитывая, что примерно 30-35 млн российского населения с учетом мигрантов [1] либо исповедуют ислам, либо тесно связаны с исламскими традициями семейных отношений, любое оценочно-регулятивное вмешательство извне вызовет только крайне негативную реакцию. В большинстве этнокультур сформировалось свое понимание насилия и практик его применения. Это в полной мере относится и к «кодексу чести», выполняющему важные социокультурные функции.

Семейный быт, отношения полов, воспитание детей представляют собой «тонкую ткань» сочетания народных традиций и гражданско-правового регулирования, определяемого Семейным и Гражданским кодексами Российской Федерации. Внедрение новых правил грозит резким разрывом культурно-бытовых отношений по этническим и конфессиональным параметрам с тяжелыми социальными последствиями.

В качестве третьей цели возможно констатировать модификацию и политизацию деятельности институтов гражданского общества, которые представлены некоммерческими и общественными объединениями, а также обеспечения контроля над ними с использованием новых гуманитарных концепций, социокультурных стилей, образцов поведения и норм международного права. Институтам гражданского общества в такой ситуации отводится исключительно роль оппонентов социально-профилактических и правоохранительных структур, власти, с претензией на монополизацию общественного мнения.

В ситуации принятия под давлением данного лобби упомянутого закона, деятельность таких организаций обретает нормативно-правовую базу. Использование этого ресурса, инициирование и легитимизация различных сообществ борцов «за» и «против» в итоге приведет к созданию параллельной системы правоприменительно-профилактической деятельности, направленной на девальвацию и последующее разрушение института традиционной семьи. Данный проект призван отобрать значительное количество функций, позволяющих квалифицировать государственные институты как действующие в интересах всего общества. И, как следствие, присвоение себе псевдо-права принимать решения от «лица народа». Наибольшую активность в продвижении этих идей проявляет «Консорциум женских неправительственных объединений» (КЖНО), «Кризисный центр "АННА"» (финансируемый из фонда Форда), «борющийся за гендерные права» в Российской Федерации, ЛГБТ-сообщество и ряд других формирований.

Четвертой целью становится ценностная модификация пространства культуры детства. Проблема насилия, в том числе и родительского, здесь обретает особую значимость. Как отмечалось выше, криминологическая и девиантологическая конвенциональность «насилия» искусственно разбирается по объектам применения превентивных практик. Не исключено, что за проектом закона о профилактике семейного насилия последуют проекты о профилактике насилия в школах, иных типах учебных заведений, возможно - в художественно-творческих структурах (например, в кинопроизводстве) и так далее, в зависимости от фантазии заказчиков. B качестве субъектов насильственных действий здесь будут позиционироваться (и, судя по соцсетям, уже являются) учителя, воспитатели, отдельные учащиеся-насильники. В качестве жертв - ученики и воспитуемые. Данная концептуальная модель дополняется самыми разнообразными формами психологических и воспитательных практик, разработанных на основе современных зарубежных методик. В их числе курсы по управлению гневом для мужчин, которые поспорили с женой или якобы унизили взглядом мимо проходящую женщину, создание и содержание кризисных центров для жертв насилия и т. п.

Традиционные системы нравственного воспитания, основанные на принципах коллективизма, взаимопомощи и ответственности определяются как морально устаревшие и непригодные. Педагогический концепт «детоцентризма», реализуемый в европейских практиках семейного воспитания, находит свое отражение в приоритете прав ребенка перед правами родителей, утверждении новых гендерных представлений. Дисциплина, выполнение обязанностей детьми могут быть квалифицированы в качестве формы принуждения - семейного насилия с вытекающими правовыми последствиями, вплоть до изъятия из семьи.

В результате достижения обозначенных целей возможно создание новой социокультурной стратегии деконструкции существующей, при всех ее достоинствах и недостатках, системы социальнопрофилактической деятельности и семейного воспитания. Инструментарием данной деконструкции является якобы новая гуманитарная технология 


\section{А. А. Сукало}

борьбы с насилием в отношении женщин и борьбы с домашним насилием. Основным субъектом часть институтов гражданского общества, общественных движений, некоммерческих организаций, реализующих проекты дерегулирования российского социума. Это предполагает передачу ряда государственных функций в руки некоммерческих организаций и бизнес-структур (специализирующихся на помощи женщинам, специалистам по гендерной идентичности, защитникам прав сексменьшинств) под лозунгами формирования открытого общества, продвижения демократии и необходимости трансляции проблем профилактики насилия в политическую плоскость.

Подводя предварительные итоги рассмотрения совокупности проблем, связанных с актуализацией в общественном информационном пространстве необходимости совершенствования профилактики отдельных видов насилия, возможно констатировать следующее.

1. Проблема профилактики насилия, во всех его проявлениях, должна рассматриваться как профессиональная деятельность в рамках реализуемой в Российской Федерации стратегии государственной культурной политики на период до 2030 г. и в соответствии с охранно-защитной моделью системы организации социальной превенции, обеспечиваемой законодательной базой и правоохранительными структурами. Институты гражданского общества способны выполнять дополнительные к основной, в достаточно широком диапазоне, функции неспециализированных субъектов социальной профилактики в соответствии с их уставами. Полномочия общественных, благотворительных, некоммерческих организаций не могут выходить за рамки действующего законодательства. Очевидно, соответствующую оценку должны получать и разворачиваемые в СМИ кампании, информационные вбросы, псевдо-расследования. Необходимо предусмотреть и защиту от вмешательства в деятельность профессионалов самозванных «борцов с насилием».

2. Семейные отношения в отечественной традиции исторически складывались на основе ряда культов: взаимной любви и уважения к женщине, почитания женщины-матери, ответственности отца, заботы о детях, помощи старшим, семейной чести и достоинства, а в более поздний, начиная с советского периода, и равноправия полов. Культура семьи, семейных взаимоотношений в процессе своего развития интегрировала различные ценностные системы - философско-этические, религиозные, социальные. В отношении воспитания детей сло- жились традиции дисциплины, ответственности, семейной солидарности. В российском социуме сам институт семьи и брака, его важность как системообразующего основания общества не вызывала сомнения. Безусловно, современная семья существует в ином социокультурном пространстве, испытывает серьезные трудности в связи с модификацией ее функций, требует серьезной социальной защиты и поддержки.

В обозначенном ракурсе правовая, ценностно-информационная защита семьи на конституционно-законодательном, информационно-медийном, психолого-педагогическом, культурном уровнях, материальная поддержка и демографическая политика крайне необходимы как системная, продуманная, целенаправленная деятельность всех общественных структур. Такая социальная и культурная стратегии, обеспеченные комплексом организационных, психолого-педагогических, профилактических практик, будут способствовать упрочению семьи в качестве действенного института современного российского общества.

\section{Список литературы}

1. Дорофеев И. П. Сколько в России мусульман. URL: https://dedadi.ru/obshhestvo/skolko-v-rossii-musulman.html (дата обращения: 09.04.2020).

2. Стратегия государственной культурной политики на период до 2030 года: утверждена распоряжением Правительства РФ от 29.02.2016 г. № 326-р (в ред. распоряжения Правительства РФ от 30.03.2018 г. № 551-p). URL: https:// www.garant.ru/products/ipo/prime/doc/71243400/. (дата обращения: 31.03.2020).

3. Федеральный закон от 19 мая 1995 г. № 82-Ф3 «Об общественных объединениях»: Принят Гос. Думой 14.04.1995 г. с изм. и доп. в ред. от 13.12.2019 г. URL: https:// base.garant.ru/10164186/ (дата обращения: 31.03.2020).

\section{References}

1. Dorofeev I. P. How much in Russia is Moscow. URL: https://dedadi.ru/obshhestvo/skolko-v-rossii-musulman.html (accessed: Apr.04.2020) (in Russ.).

2. Strategy of the state cultural policy for the period until 2030: approved by the order of the Government of the Russian Federation of Febr. 29.2016 № 326-p (as amended by the order of the Government of the Russia of Mar.30.2018 № 551-p). URL: https://www.garant.ru/products/ipo/prime/doc/71243400/. (accessed: Mar.31.2020) (in Russ.).

3. Federal law of May 19.1995 № 82-Ф3 «On Public Associations»: adopted by the State Duma on Apr.14.1995 with amend. and add. on Dec.13.2019. URL: https://base.garant. com/10164186/ (accessed: Mar.31.2020) (in Russ.). 